\title{
RATIONALE OF THE COX MAZE PROCEDURE FOR ATRIAL FIBRILLATION DURING REDO MITRAL VALVE OPERATIONS
}

Junjiro Kobayashi, MD

Yoshio Kosakai, MD

Fumitaka Isobe, MD

Yoshikado Sasako, MD

Kiyoharu Nakano, MD

Kiyoyuki Eishi, MD

Yasunaru Kawashima, MD
Objective: The frequency of reoperation for mitral valve diseases with chronic atrial fibrillation has increased steadily. This study examined the rationale for using the Cox maze operation for atrial fibrillation during redo mitral valve operations. Methods: Between June 1992 and July 1995, we performed the maze procedure in 42 patients as a concomitant operation with redo mitral valve surgery (maze group). Associated procedures were tricuspid valve surgery in 27 patients and aortic valve surgery in 15 patients. The mean age at operation was $57.3 \pm 9.7$ years, and the mean interval from the previous operation was $14.3 \pm 10.5$ years. The mean follow-up period after the maze procedure was $25.5 \pm 10.8$ months. Atrial fibrillation was present at the time of the previous operation in 29 patients (69\%). Results: Neither hospital death nor late death occurred. Sinus rhythm was regained in 28 patients $(67 \%)$, and an atrial A-wave was detected in 21 patients $(50 \%)$ by pulsed Doppler study. Patients in whom sinus rhythm was restored had a shorter history of atrial fibrillation $(9.0 \pm 6.0$ years vs $15.9 \pm 4.6$ years, $p=0.0009)$, a larger $f$-wave on lead $V_{1}$ of the electrocardiogram $(0.18 \pm 0.10 \mathrm{mV}$ vs $0.10 \pm 0.08 \mathrm{mV}, p=0.017)$, and a smaller cardiothoracic ratio $(63 \% \pm 8 \%$ vs $67 \% \pm 5 \%, p=0.049)$ than patients with persistent atrial fibrillation. During the same period, 54 patients underwent mitral valve reoperation without the maze procedure (control group). The aortic crossclamp and cardiopulmonary bypass times were slightly longer $(p=$ 0.048 and $p=0.012)$ in the maze group $(133 \pm 28$ minutes and $221 \pm 43$ minutes) than in the control group ( $126 \pm 65$ minutes and $197 \pm 78$ minutes). There was no significant difference in the amount of chest tube drainage or transfusion between the two groups $(890 \pm 510 \mathrm{ml}$ and $2120 \pm 1600 \mathrm{ml}$, respectively, in the maze group and $840 \pm 480 \mathrm{ml}$ and $2140 \pm 1760 \mathrm{ml}$, respectively, in the control group). It was not necessary to reopen the chest for bleeding significantly more often in one group than in the other (14\% in the maze group and $7 \%$ in the control group), and it was possible to operate without transfusion with the same frequency in the two groups $(17 \%$ in the maze group and $20 \%$ in the control group). Conclusion: These results suggest that the maze procedure should be considered in selected patients who have a high possibility of regaining sinus rhythm during redo mitral valve operations. (J Thorac Cardiovasc Surg 1996;112:1216-22)
$\mathrm{T}_{\mathrm{re}}^{\mathrm{he}}$ he incidence of mitral valve reoperation has recently increased ${ }^{1,2}$ owing to the palliative nature of the initial mitral valve repair of closed or open mitral commissurotomy. Progression of the aortic or tricuspid valve disease, structural deterio-

From the Department of Cardiovascular Surgery, National Cardiovascular Center, Osaka, Japan.

Read at the Seventy-sixth Annual Meeting of The American Association for Thoracic Surgery, San Diego, Calif., April 28-May 1, 1996.

Received for publication May 6, 1996; revisions requested June 11, 1996; revisions received July 24, 1996; accepted for publication July 24, 1996. ration of the bioprosthetic valve, and infection of the prosthetic valve are other causes for reoperation. Atrial fibrillation (AF) is frequently associated in these patients, and sinus rhythm seldom returns even after successful repair of the mitral valve lesion. With persistent AF, the risk of thromboem-

Address for reprints: Junjiro Kobayashi, MD, Department of Cardiovascular Surgery, National Cardiovascular Center, 5-7-1 Fujishiro-dai, Suita-city, Osaka 565, Japan.

Copyright (C) 1996 by Mosby-Year Book, Inc.

$0022-5223 / 96 \$ 5.00+0 \quad \mathbf{1 2 / 6 / 7 6 8 2 4}$ 
Table I. List of operations done before the maze procedure

\begin{tabular}{lc}
\hline \multicolumn{1}{c}{ Operation } & No. of patients \\
\hline MVR & 15 \\
OMC for MS & 8 \\
Mitral valve repair for MR & 6 \\
MVR and AVR & 4 \\
CMC & 3 \\
Mitral valve repair and ASD closure & 3 \\
OMC and AVR & 2 \\
Mitral and aortic valve repair & 1 \\
Total & 42 \\
\hline
\end{tabular}

All valve replacement was performed with a biologic valve except in one case. Two patients had undergone open mitral commissurotomy previously. $M V R$, Mitral valve replacement; $O M C$, open mitral commissurotomy; $M S$, mitral stenosis; $M R$, mitral regurgitation; $A V R$, aortic valve replacement; $C M C$, closed mitral commissurotomy; $A S D$, atrial septal defect.

bolism increases and the loss of left atrial contraction impairs left ventricular function.

The maze procedure was developed by $\mathrm{Cox},{ }^{3}$ and its modifications have been widely performed during the past few years as a concomitant procedure with mitral valve operations. ${ }^{4-9}$ However, conducting the maze procedure simultaneously with redo mitral valve surgery is still controversial, because redo valve operations have a considerably higher operative mortality than primary valve operations. In the present study, we examined the efficacy and risk of the maze procedure for AF during redo mitral valve surgery.

\section{Patients and methods}

Patients. Between June 1992 and July 1995, 42 patients with $\mathrm{AF}$ underwent redo mitral valve operations with the maze procedure (maze group). The patients are composed of 21 men and 21 women, and their ages at operation ranged from 23 to 71 years with an average of $57.3 \pm 9.7$ years (mean \pm standard deviation). The interval from the previous operation was 1.4 to 33 years with an average of $14.3 \pm 10.5$ years. The duration of $\mathrm{AF}$ ranged from 10 months to 29 years with an average of $11.3 \pm 3.4$ years. AF was already present at the time of the previous operation in 29 patients $(69 \%)$. The previous operations are listed in Table I. Two patients underwent a third operation. The causes of redo mitral valve operations were bioprosthetic valve degeneration in 19 patients, mitral regurgitation in 10 , mitral restenosis with regurgitation in 9, and pure mitral restenosis in 4 . Concomitant valve diseases were aortic valve disease in 14 patients and tricuspid regurgitation in 23 . Forty patients had chronic sustained $\mathrm{AF}$, and 2 patients had paroxysmal $\mathrm{AF}$ or atrial flutter. Preoperative electrocardiography (ECG) was recorded, and the voltage of the $f$-wave in lead $V_{1}$ was measured. New York Heart Association functional class was I or II in 22 patients and III or IV in 20. The cardiothoracic ratio was also measured before the opera-
Table II. Simultaneous operations with the maze procedure

\begin{tabular}{lc}
\multicolumn{1}{c}{ Operations } & No. of paitents \\
\hline MVR and TAP & 20 \\
MVR and AVR with or without TAP & 8 \\
MVR & 7 \\
MVR with other procedures & 3 \\
Mitral valve repair with or without & 3 \\
$\quad$ other valve repair & 1 \\
Mitral valve repair and AVR & 42 \\
Total &
\end{tabular}

All valve replacement was performed with a mechanical valve. Three patients underwent only valve repair. All abbreviations are the same as in Table I. TAP, Tricuspid annuloplasty.

tion, and the left atrial size was determined by echocardiography.

Simultaneous procedures with the maze operation are listed in Table II. All valves were replaced with a mechanical valve. As for the maze procedure, we performed Kosakai's modified maze procedure in 37 patients, the modified Cox maze II procedure in 2 , and the modified Cox maze III procedure in 3. The precise technique of the operation was described previously.7, 10 Cardiopulmonary bypass was instituted with ascending aortic cannulation and bicaval cannulation after partial release of the adhesion. The heart was completely dissected out for the maze procedure before the aorta was crossclamped. All patients had mild systemic hypothermia $\left(29^{\circ}\right.$ to $32^{\circ} \mathrm{C}$ ), antegrade infusion of St. Thomas' Hospital cardioplegic solution every 30 minutes, and topical cooling with ice slush. In five patients with severe adhesions on the left side of the left atrium, the latter was not completely separated from the left pulmonary veins. Cryoablation was performed on the undivided edge of that side. The right atrial procedure was performed before crossclamping of the aorta and arrest of the heart with St. Thomas' Hospital cardioplegic solution. Aprotinin was used during cardiopulmonary bypass in 17 patients, with an initial administration of 1 million units followed by $1 / 2$ million units every hour until the termination of bypass. When the left and right atrial appendages were already resected, the base of the each appendage was merely cryoablated.

Control group. The patients who underwent redo mitral valve operations without the concomitant maze procedure during the same period (control group) were compared with the maze group. This control group consisted of 54 patients of matching age, sex, severity of diseases, and other profiles (Table III). Forty-one patients $(76 \%)$ had $\mathrm{AF}$. The reason for avoiding the maze procedure in these patients was no f-wave or low ventricular rate (or both), left atrial wall calcification, serious complication, and lack of an informed consent form for the maze procedure in the earlier period. The reasons for redo mitral valve surgery were bioprosthetic valve degeneration in 41 patients, mitral regurgitation in 5, mitral restenosis with regurgitation in 5 , and pure mitral restenosis in 3. Concomitant valve diseases were aortic valve disease in 25 patients and tricuspid regurgitation in 25 . The operative procedures were mitral valve replacement 
Table III. Patient profile of the maze and the control groups

\begin{tabular}{|c|c|c|c|}
\hline Characteristics & $\begin{array}{c}\text { Maze } \\
\text { group } \\
(n=42)\end{array}$ & $\begin{array}{c}\text { Control } \\
\text { group } \\
(n=54)\end{array}$ & $p$ Value \\
\hline Age at operation (yr) & $57.3 \pm 9.7$ & $61.2 \pm 10.0$ & NS \\
\hline $\begin{array}{c}\text { Interval after previous } \\
\text { operation (yr) }\end{array}$ & $14.3 \pm 10.5$ & $10.8 \pm 3.3$ & NS \\
\hline $\operatorname{Sex}(\mathrm{M} / \mathrm{F})$ & $21 / 21$ & $23 / 31$ & NS \\
\hline NYHA class III, IV & $20(48 \%)$ & $30(56 \%)$ & NS \\
\hline Rheumatic heart disease & $36(86 \%)$ & $49(91 \%)$ & NS \\
\hline Third time operation & $2(4.8 \%)$ & $4(7.4 \%)$ & NS \\
\hline Presence of tricupsid lesion & $23(55 \%)$ & $25(46 \%)$ & NS \\
\hline Presence of aortic lesion & $14(33 \%)$ & $25(46 \%)$ & NS \\
\hline \multicolumn{4}{|l|}{ Presence of $\mathrm{AF}$} \\
\hline Last operation & $29(69 \%)$ & $36(67 \%)$ & NS \\
\hline Present operation & $40(95 \%)$ & $41(76 \%)$ & NS \\
\hline Cardiothoracic ratio $(\%)$ & $64 \pm 7$ & $67 \pm 9$ & NS \\
\hline \multicolumn{4}{|l|}{$\begin{array}{c}\text { Cardiac measurement by } \\
\text { echocardiography }\end{array}$} \\
\hline $\mathrm{LAD}(\mathrm{mm})$ & $57 \pm 8$ & $58 \pm 14$ & NS \\
\hline LVEDD (mm) & $52 \pm 9$ & $52 \pm 9$ & NS \\
\hline $\operatorname{LVESD}(\mathrm{mm})$ & $35 \pm 9$ & $34 \pm 9$ & NS \\
\hline \multicolumn{4}{|l|}{ Blood examination } \\
\hline Creatinine $(\mathrm{mg} / \mathrm{dl})$ & $0.8 \pm 0.2$ & $1.2 \pm 2.8$ & NS \\
\hline $\mathrm{BUN}(\mathrm{mg} / \mathrm{dl})$ & $17 \pm 5$ & $21 \pm 9$ & NS \\
\hline Hemoglobin $(\mathrm{g} / \mathrm{dl})$ & $12.6 \pm 2.3$ & $12.0 \pm 2.2$ & NS \\
\hline Platelet $(\times 1000 / \mu l)$ & $186 \pm 62$ & $147 \pm 60$ & NS \\
\hline Total bilirubin $(\mathrm{mg} / \mathrm{dl})$ & $1.2 \pm 0.7$ & $1.5 \pm 0.9$ & NS \\
\hline Aprotinin use & $17(40 \%)$ & $25(46 \%)$ & NS \\
\hline
\end{tabular}

$M F$, Male/female; $N Y H A$, New York Heart Association; $A F$, atrial fibrillation; $L A D$, left atrial dimension; $L V E D D$, left ventricular end-diastolic dimension; $L V E S D$, left ventricular end-systolic dimension; $B U N$, blood urea nitrogen; $N S$, not significant.

(MVR) with tricuspid annuloplasty in 15 patients, MVR and aortic valve replacement with or without tricuspid annuloplasty in 18, MVR in 7, MVR and tricuspid valve replacement in 7, MVR, aortic valve replacement, and tricuspid valve replacement in 3 , MVR and aortic valvuloplasty in 2, and mitral valvuloplasty in 2 . All valves were replaced with a mechanical valve except in one case in which double valve replacement with porcine bioprostheses was done.

Data collection. The status of patients was determined by referring to the medical records and correspondence with the responsible physicians. All the cardiac and noncardiac events were recorded in detail. Patients were followed up by ECG, chest roentgenogram, and echocardiography with pulsed Doppler study every 3 months. We defined the sinus rhythm on ECG 6 months after the operation if the P-wave was present. The presence of an A-wave through the mitral and tricuspid valves by pulsed Doppler study was decided by the independent analysis of the cardiologists. The mean follow-up period after the redo mitral valve operation was $25.5 \pm 10.8$ months for the maze group and $29.2 \pm 11.3$ months for the control group. Three patients in the maze group and two patients in the control group were free from anticoagulation therapy.
Statistical analysis. Continuous variables were compared by the Wilcoxon rank sum test, and the discrete variables were analyzed by Fisher's exact test. Differences were considered statistically significant when the $p$ value was less than 0.05 .

\section{Results}

No hospital death or late deaths occurred in the maze group. Two reoperations were done for residual mitral regurgitation and one redo MVR for prosthetic valve endocarditis. Sinus rhythm was restored in 28 patients $(67 \%)$, and an atrial A-wave was detected in 21 patients (50\%) by pulsed Doppler study. In five patients, an A-wave was observed only in the transtricuspid flow. AF persisted in eight patients. Other rhythms were persistent atrial flutter in two and junctional rhythm in four, three of whom eventually required implantation of a DDD pacemaker. Among 29 patients who had AF after the previous operation, sinus rhythm was restored in $12(41 \%)$. Of five patients whose pulmonary veins were not completely dissected from the left atrium on the left side with the substitution of cryoablation, none regained normal sinus rhythm. Patients who regained sinus rhythm had a shorter history of $\mathrm{AF}(9.0 \pm 6.0$ years vs $15.9 \pm 4.6$ years, $p=0.0009$ ), a larger $\mathrm{f}$-wave on lead $\mathrm{V}_{1}$ of the ECG $(0.18 \pm 0.10 \mathrm{mV}$ vs $0.10 \pm 0.08 \mathrm{mV}, p=0.017)$, and a smaller cardiothoracic ratio $(63 \% \pm 8 \%$ vs $67 \% \pm$ $5 \%, p=0.049)$ than patients with persistent $\mathrm{AF}$ (Table IV).

The aortic crossclamp time and cardiopulmonary bypass time were slightly longer $(p=0.048$ and $p=$ $0.012)$ in the maze group (133 \pm 28 minutes and $221 \pm 43$ minutes) than in the control group (126 \pm 65 minutes and $197 \pm 78$ minutes). The median aortic crossclamp time was 136 minutes in the maze group and 115 minutes in the control group. The median cardiopulmonary bypass time was 216 minutes in the maze group and 189 minutes in the control group. There was no significant difference in the amount of chest tube drainage or transfusion between the two groups $(890 \pm 510 \mathrm{ml}$ and $2120 \pm$ $1600 \mathrm{ml}$, respectively, in the maze group and $840 \pm$ $480 \mathrm{ml}$ and $2140 \pm 1760 \mathrm{ml}$, respectively, in the control group). It was not necessary to reopen the chest for bleeding significantly more often in one group than in the other (14\% in the maze group and $7 \%$ in the control group), nor was there a difference between groups in the need for transfusion (17\% in the maze group; $20 \%$ in the control group) (Table $\mathrm{V})$. There were no significant differences in mortal- 
Table IV. Comparison between patients with and without restored sinus rhythm

\begin{tabular}{|c|c|c|c|}
\hline Variables & Sinus rhythm $(+)$ & Sinus rhythrn (-) & $p$ Value \\
\hline No. of patients & 28 & 14 & \\
\hline Age at operation $(\mathrm{yr})$ & $57.8 \pm 10.0$ & $56.1 \pm 9.3$ & NS \\
\hline $\operatorname{Sex}(M / F)$ & $16 / 12$ & $5 / 9$ & NS \\
\hline Rheumatic heart disease & $23(82 \%)$ & $13(94 \%)$ & NS \\
\hline Duration of AF (yr) & $9.0 \pm 6.0$ & $15.9 \pm 4.6$ & $p=0.0009$ \\
\hline Presence of AF at the previous operation & $21(75 \%)$ & $8(57 \%)$ & NS \\
\hline NYHA class III, IV & $14(50 \%)$ & $6(43 \%)$ & NS \\
\hline Voltage of $\mathrm{f}$-wave on lead $V_{1}(\mathrm{mV})$ & $0.18 \pm 0.10$ & $0.10 \pm 0.08$ & $p=0.017$ \\
\hline Cardiothoracic ratio $(\%)$ & $63 \pm 8$ & $67 \pm 5$ & $p=0.049$ \\
\hline Presence of tricuspid lesion & $13(46 \%)$ & $10(71 \%)$ & NS \\
\hline \multicolumn{4}{|l|}{$\begin{array}{l}\text { Cardiac measurements by echocardiography } \\
\text { before the maze procedure }\end{array}$} \\
\hline $\mathrm{LAD}(\mathrm{mm})$ & $57 \pm 9$ & $57 \pm 6$ & NS \\
\hline LVEDD (mm) & $52 \pm 10$ & $52 \pm 10$ & NS \\
\hline $\operatorname{LVESD}(\mathrm{mm})$ & $35 \pm 8$ & $35 \pm 9$ & NS \\
\hline \multicolumn{4}{|l|}{$\begin{array}{l}\text { Cardiac measurements by echocardiography } \\
\text { after the maze procedure }\end{array}$} \\
\hline LAD $(\mathrm{mm})$ & $43 \pm 6$ & $45 \pm 6$ & NS \\
\hline LVEDD (mm) & $48 \pm 9$ & $49 \pm 9$ & NS \\
\hline $\operatorname{LVESD}(\mathrm{mm})$ & $35 \pm 9$ & $36 \pm 12$ & NS \\
\hline
\end{tabular}

$M / F$, Male/female; $A F$, atrial fibrillation; $L A D$, left atrial dimension; $L V E D D$, left ventricular end-diastolic dimension; $L V E S D$, left ventricular end-systolic dimension; $N S$, not significant.

Table V. Results of operations in the maze and control groups

\begin{tabular}{|c|c|c|c|}
\hline & $\begin{array}{l}\text { Maze group } \\
(n=42)\end{array}$ & $\begin{array}{l}\text { Control group } \\
\quad(n=54)\end{array}$ & $p$ Value \\
\hline ACC time (min) & $133 \pm 28[136]$ & $121 \pm 44[115]$ & $p=0.048$ \\
\hline CPB time (min) & $211 \pm 43[216]$ & $197 \pm 78[189]$ & $p=0.012$ \\
\hline Chest tube drainage* $(\mathrm{ml})$ & $890 \pm 510[800]$ & $840 \pm 480[820]$ & NS \\
\hline Blood transfusion (ml) & $2120 \pm 1600[2150]$ & $2140 \pm 1760[2090]$ & NS \\
\hline No transfusion & $7(17 \%)$ & $11(20 \%)$ & NS \\
\hline \multicolumn{4}{|l|}{ Mortality } \\
\hline Hospital death & $0(0 \%)$ & $4(7.4 \%)$ & NS \\
\hline Late death & $0(0 \%)$ & $2(3.7 \%)$ & NS \\
\hline \multicolumn{4}{|l|}{ Morbidity } \\
\hline Chest reopening for bleeding & $6(14 \%)$ & $4(7.4 \%)$ & NS \\
\hline Mediastinitis & $0(0 \%)$ & $2(3.7 \%)$ & NS \\
\hline \multicolumn{4}{|l|}{ Late complications } \\
\hline Thromboembolism & $0(0 \%)$ & $1(1.9 \%)$ & NS \\
\hline $\mathrm{CSH}$ & $2(4.8 \%)$ & $0(0 \%)$ & NS \\
\hline Infective endocarditis & $1(2.4 \%)$ & $1(1.9 \%)$ & NS \\
\hline Reoperation & $2(4.8 \%) \dagger$ & $2(3.7 \%) \ddagger$ & NS \\
\hline
\end{tabular}

Brackets indicate median value. $A C C$, aortic crossclamp; $C P B$, cardiopulmonary bypass; CSH, chronic subdural hematoma.

*For 24 hours after admission into the intensive care unit.

$\dagger$ Residual mitral regurgitation.

$\$$ Perivalvular leakage.

ity, morbidity, and the incidence of late complications between the two groups.

\section{Discussion}

The purpose of the maze procedure is to convert AF to sinus rhythm and to restore the atrial booster pump function. In the present study, $67 \%$ of the patients regained sinus rhythm, a lower percentage than that achieved during maze procedures performed during the initial mitral valve operation in our institute (84\%, unpublished data). The pulsed Doppler study detected left atrial contraction in $38 \%$ and right atrial contraction in $50 \%$. The incidence of A-wave detection was $81 \%$ for the transtricuspid flow and $69 \%$ for the transmitral flow in patients who underwent the maze procedure with 
the primary mitral valve operation (unpublished data). Therefore satisfactory ECG and hemodynamic effects of the maze procedure were less frequent after the redo mitral valve operation than after the primary mitral valve operation. This is a significant problem, because thromboembolism remains a risk in patients in whom sinus rhythm and atrial contraction are not restored.

There were three kinds of failure in sinus rhythm recovery. One kind is sinus node dysfunction, which necessitates atrial pacemaker implantation. Preservation of the arterial supply to the sinus node by modifying the incision could not prevent sinus node dysfunction completely. Sinus node dysfunction may be caused by damage to the sinus node itself by rheumatic degeneration, surgical trauma, persistent high atrial pressure, or right atrial enlargement such as after a Senning or Fontan operation. ${ }^{11,12}$ Another type is $\mathrm{AF}$ and atrial flutter, which were presumably the result of a shorter atrial refractory time or microreentry circuits. Another possibility is the less than optimal substitution of cryoablation for a surgical incision, especially in patients with severe adhesions in whom the left atrium could not be separated from the left pulmonary veins.

Sacrifice of Bachmann's bundle may delay the conduction from the sinus node to the left atrium, and the left ventricle may contract at the same time as the left atrium. ${ }^{13}$ The absence of atrial contraction was probably due to a fibrotic and calcified degeneration of the left atrium. This may explain the more frequent detection of the A-wave in the transtricuspid flow by the pulsed Doppler study than in the transmitral flow because our modified maze procedure-similar to the Cox maze III procedure-does not sacrifice Bachmann's bundle. According to a preliminary study by the cardiologists in our institute, left atrial contraction appeared even 6 months after the maze operation, and the left atrium may regain contraction with time. Williams and associates ${ }^{14}$ reported that right atrial-right ventricular synchrony with preserved right atrial function could result in forward cardiac output regardless of the left atrium in the animal model. The right atrial contraction is thought to contribute to a higher cardiac output and lower central venous pressure.

The risk factors for failure to regain sinus rhythm were duration of $A F$, amplitude of $f$-wave in lead $V_{1}$, and cardiothoracic ratio. These results almost agree with those of our previous studies. ${ }^{7}, 10$ The dimension of the left atrium by echocardiography was not related to the recovery of the sinus rhythm in the present study. However, cardiothoracic ratio was reflected by the enlargement of the left and right atria. An enlarged left atrium may induce AF even after the atrium has been divided by incision or cryoablation because the separate compartments of the atrium were still large enough to make a reentry. Therefore we resected the left atrium and took enough bite stitches so as not to make the segment longer than $4 \mathrm{~cm}$. The $\mathrm{f}$-wave is a sum of the total electrical activity of the atrial muscles, and the amplitude is thought to reflect degree of degeneration of the atrium. Tricuspid regurgitation was observed slightly more frequently in patients without sinus rhythm, but the difference was not statistically significant. Damage to the sinus node and right atrium may result from pressure and volume overload in these patients.

Reoperative mitral valve surgery is usually associated with a higher operative mortality and morbidity than the primary mitral valve operation. There was no hospital death in the maze group. The incidence of morbidity was similar to that in the control group. The aortic crossclamp time and cardiopulmonary bypass time were significantly longer in the maze group than in the control group, but postoperative bleeding, amount of transfusion, and other types of morbidity were similar in the two groups. Reopening the chest for bleeding was necessary slightly more often in the maze group, but the difference was not statistically significant. The maze procedure necessitated complete dissection of the entire heart from the surrounding tissue. Especially in reoperations after closed mitral commissurotomy, the pericardium and the pleura were sometimes deficient, and the left lung was tightly adherent to the heart. The risk of bleeding before and after the redo mitral valve operation increased if the adhesion was very tight. We used aprotinin in $40 \%$ of patients, because it reduces intraoperative and postoperative bleeding. ${ }^{15}$ Thus we are able to avoid or reduce blood transfusion with prophylactic use of aprotinin in the maze procedure.

Careless elevation of the cardiac apex during the dissection may increase the risk of tearing the left ventricle if the strut of the bioprosthetic valve is incorporated into the ventricular muscle. ${ }^{16}$ Nevertheless, dissection of the whole heart had some merit. In addition to cardioplegic solution, ice slush on the surface of the ventricle can result in satisfactory myocardial preservation with mild hypothermia. Mitral exposure was as good as that obtained with the transseptal superior approach, which may 
sacrifice the right and left sinus node arteries. ${ }^{17}$ Removing air from the heart was easy, and bypass time after aortic unclamping could be shortened. The median aortic crossclamp and cardiopulmonary bypass times in the maze group were only 20 to 30 minutes longer than in the control group. Although the maze procedure usually took an additional 40 to 50 minutes, MVR could be performed as easily and quickly as with "bench" surgery.

No cardiac complications were related to the maze procedure itself, and no thromboembolic episode was detected though the follow-up period was short. Chua and associates ${ }^{18}$ reported that $80 \%$ of patients with preoperative chronic AF had persistent $\mathrm{AF}$ rhythm after mitral valve repair with a mean follow-up of 2.6 years. The remaining $20 \%$ of patients with sinus rhythm or paroxysmal AF might be treated with antiarrhythmic drugs, which are proarrhythmic by themselves. In our institute, the defibrillation rate in patients who underwent only a mitral valve operation was also $15 \%$ in 1988 and 1989.

The drawback of the present study was that the maze group and the control group were not separated at random. In principle, we recommended the maze procedure for all patients with $\mathrm{AF}$ in the control group, irrespective of the size of the left atrium and the history of AF. However, we could not obtain informed consent from the patients, especially in the early period of the present study, because the data were not convincing enough. The other problem was the relatively short follow-up period of $2 \frac{1}{2}$ years. We have to follow up the patients for 5 to 10 years to assess the efficacy of the maze procedure for the prevention of thromboembolism and bleeding in patients with mechanical valve replacement and anticoagulation therapy.

Comparing the benefits and efficacy versus the risk of the maze procedure during the redo mitral valve operation, the maze procedure should be restricted to patients with a high possibility of recovering sinus rhythm and to patients who undergo mitral valve repair without receiving anticoagulant therapy. McCarthy and associates ${ }^{6}$ recommended that the maze procedure should be performed in patients with good ventricular function. However, inasmuch as atrial contraction is very important to the failing heart, we think that the maze procedure should be performed concomitantly with MVR while preserving the mitral valve apparatus for moderately depressed left ventricular function.

\section{REFERENCES}

1. Cohn LH, Aranki SF, Rizzo RJ, et al. Decrease in operative risk of reoperative valve surgery. Ann Thorac Surg 1993;56: 15-21.

2. Najafi H, Guynn T, Najafi C, et al. Declining risk of reoperative valvular surgery. J Card Surg 1995;10:185-97.

3. Cox JL. The surgical treatment of atrial fibrillation. IV. Surgical technique. J Thorac Cardiovasc Surg 1991;101:58492.

4. Hioki M, Ikeshita M, Iedokoro Y, et al. Successful combined operation for mitral stenosis and atrial fibrillation. Ann Thorac Surg 1993;55:776-8.

5. Cox JL, Boineau JP, Schuessler RB, et al. Five-year experience with the maze procedure for atrial fibrillation. Ann Thorac Surg 1993;56:814-24.

6. McCarthy PM, Castle LW, Maloney JD, et al. Initial experience with the maze procedure for atrial fibrillation. J Thorac Cardiovase Surg 1993;105:1077-87.

7. Kosakai $\mathrm{Y}$, Kawaguchi AT, Isobe F, et al. Cox maze procedure for chronic atrial fibrillation associated with mitral valve disease. J Thorac Cardiovsac Surg 1994;108:1049-55.

8. Itoh $\mathrm{T}$, Okamoto $\mathrm{H}$, Nimi $\mathrm{T}$, et al. Left atrial function after Cox's maze operation concomitant with mitral valve operation. Ann Thorac Surg 1995;60:354-60.

9. Gregori F, Cordeiro CO, Couto WJ, et al. Cox maze operation without cryoablation for the treatment of chronic atrial fibrillation. Ann Thorac Surg 1995;60:361-4.

10. Kosakai Y, Kawaguchi AT, Isobe F, et al. Modified maze procedure for patients with atrial fibrillation undergoing simultaneous open heart surgery. Circulation 1995; 92(Suppl):II359-64.

11. Martin TC, Smith L, Hernandez A, Weldon CS. Dysrhythmias following the Senning operation for dextro-transposition of the great arteries. J Thorac Cardiovasc Surg 1983;85: 928-32.

12. Gewilling M, Wyse RK, de Leval MR, Deanfield JE. Early and late arrhythmias after the Fontan operation: predisposing factors and clinical consequences. Br Heart J 1992;67: 72-9.

13. Cox JL, Boineau JP, Schuessler RB, et al. Modification of the maze procedure for atrial flutter and atrial fibrillation. I. Rationale and surgical results. J Thorac Cardiovasc Surg 1995;110:473-84.

14. Williams JM, Ungerleider RM, Lofland GK, Cox JL. Left atrial isolation: new technique for the treatment of supraventricular arrhythmias. J Thorac Cardiovasc Surg 1980;80:37380.

15. Harder MP, Eijsman L, Roozendaal KL, van Oeveren W, Wildevuur $\mathrm{CRH}$. Aprotinin reduces intraoperative and postoperative blood loss in membrane oxygenator cardiopulmonary bypass. Ann Thorac Surg 1991;51:936-41.

16. Dhillon JS, Randhawa GK, Pett SB. Successful repair of left ventricular rupture after redo mitral valve replacement. Ann Thorac Surg 1989;47:916-7.

17. Guiraudon GM, Ofiesh JG, Kaushik R. Extended vertical transatrial septal approach to the mitral valve. Ann Thorac Surg 1991;52:1058-62.

18. Chua YL, Schaff HV, Orszulak TA, Morris JJ. Outcome of mitral valve repair in patients with preoperative atrial fibrillation: Should the maze procedure be combined with mitral valvuloplasty? J Thorac Cardiovase Surg 1994;107: 408-15. 


\section{Discussion}

Dr. Fred A. Crawford (Charleston, S.C.). Recently at the meeting of the American Surgical Association Jim Cox summarized his entire series of maze procedures. Overall, 93\% of the patients were cured of AF by the operation alone, and the remaining $7 \%$ were cured by the addition of one drug; $94 \%$ were found to have left atrial function after the operation.

Because of the success in patients with isolated AF, the maze procedure has now been combined with other procedures in selected patients. Dr. Kobayashi and his colleagues have previously reported the combination of the maze procedure with a variety of other cardiac procedures, and today they report performing a modification of the maze procedure in 42 patients at the time of reoperative mitral valve surgery. There were no deaths in this series, attesting to their operative skills. However, only two thirds of the patients regained sinus rhythm as compared with all of those in Cox's series.

It is clear that the procedure performed by Dr. Kobayashi and his colleagues is significantly different from the current modification of the maze procedure performed by Cox. One effect of these changes is to shorten the time required to perform the operation; for example, in this series it only added 7 minutes to the crossclamp time and 24 minutes to the total pump time. Cox believes that a key part of the maze procedure is the vertical incision that connects the pulmonary vein encircling incision to the mitral valve anulus and, in particular, the ablation of all conduction across the coronary sinus. In fact, in his early patients with postoperative $\mathrm{AF}$, failure was believed to be due at the time of restudy to persistent conduction in this area. Dr. Kobayashi does not perform this incision at all; instead, he replaces it with extensive cryoablation. Dr. Kobayashi, do you believe that the relatively high failure rate in your series is related to this or to other modifications that you have made to the maze procedure, or do you believe that it is related to something else, perhaps the relatively long history of $\mathrm{AF}$ and the marked dilatation of the left atrium in these patients? If it is due to your modifications, have you considered changing so that you perform the operation more as Cox has described? If it is due to the duration of AF or to left atrial size, is there some subset of patients that can be identified before the operation in whom the maze is more likely to be unsuccessful and in whom it should therefore not be performed? Accordingly, what are your current criteria for performing the maze procedure at the time of redo mitral valve surgery and also for those patients with AF undergoing a first-time mitral valve procedure?

Finally, one of the advantages of the maze operation is not only to return the patient to sinus rhythm but to return atrial transport function to normal. Left atrial contractions were identified in only $38 \%$ of your patients. Is the addition of the maze procedure at the time of redo mitral valve surgery worth the extra effort and potential risk to the patient for this small gain?

Dr. Kobayashi. Thank you very much, Dr. Crawford, for the very important comments. These were consecutive patients; we did not select them according to the size of the left atrium or the length of their histories. We were a little less successful in restoring sinus rhythm was Dr. Cox. These patients had long-term AF with rheumatic heart disease, and I think that is the reason for the difference. Sinus rhythm was restored in $84 \%$ of the patients after primary mitral valve surgery, so I think these patients had more advanced rheumatic heart disease.

About the criteria: I did not select the patients. If we had select patients according to certain criteria, for example, left atrial size smaller than $60 \mathrm{~mm}$ in diameter, cardiothoracic ratio smaller than $65 \%$, f-wave larger than $2.0 \mathrm{~mm}$ in lead $\mathrm{V}_{1}$, and duration of AF less than 10 years, I think the success rate would be more than $95 \%$. The advantage of the maze procedure is not only the recovery of sinus rhythm but also regaining the atrial booster pump function, which is very important for the impaired left ventricular function. In the patients who underwent MVR, the maze procedure is as important as the preservation of the mitral valve apparatus, even if the patients have to have warfarin sodium. If the patient is restored to sinus rhythm, we will be able to use a relatively low prothrombin time international normalized ratio with warfarin and decrease the incidence of bleeding.

Dr. Joao Q. Melo (Carnaxide, Portugal). Dr. Kobayashi, two years ago your group presented to this Association a much higher rate of success after the maze operation in patients with mitral disease. These patients mostly had had a first operation, and most of them had recent onset of AF. I believe that your results in reoperated patients are almost the same as in the first operation, the difference being that in that cohort you were operating mostly in patients with chronic AF. If this is so, in your opinion, is it justifiable to do the operation in patients with mitral valve disease and $\mathrm{AF}$ of recent onset?

Dr. Kobayashi. Some patients with mitral valve disease who have sinus rhythm in the preoperative period will have AF in the follow-up period. Thus we had better do the maze procedure in patients with recently occurring AF. In our modification we resect the right atrium and the left atrium and make the compartment smaller than $4 \mathrm{~cm}$ in width for advanced valvular heart disease. This is very important to restore sinus rhythm if the left atrium is very enlarged and also if the right atrium is enlarged owing to tricuspid regurgitation. 